\title{
Distribution of antibody titer against Salmonella enterica among healthy individuals in nepal Bharat M Pokhrel $^{\dagger 1}$, Rajendra Karmacharya ${ }^{\dagger 1}$, Shyam K Mishra ${ }^{\dagger 1}$ and Janak Koirala*†2
}

\author{
Address: ${ }^{1}$ Tribhuvan University, Institute of Medicine, Department of Microbiology, Maharajgunj, Kathmandu, Nepal and ${ }^{2}$ Southern Illinois \\ University, School of Medicine, Department of Medicine, Division of Infectious Diseases Post Office Box - 19636 Springfield, Illinois $62794-9636$ \\ USA \\ Email: Bharat M Pokhrel - bmp268@iom.edu.np; Rajendra Karmacharya - bmp268@iom.edu.np; Shyam K Mishra - bmp268@iom.edu.np; \\ Janak Koirala* - jkoirala@siumed.edu \\ * Corresponding author †Equal contributors
}

Published: 7 January 2009

Annals of Clinical Microbiology and Antimicrobials 2009, 8: I doi:I0.1 I86/I476-07| I-8-I

This article is available from: http://www.ann-clinmicrob.com/content/8/I/I

(c) 2009 Pokhrel et al; licensee BioMed Central Ltd.

This is an Open Access article distributed under the terms of the Creative Commons Attribution License (http://creativecommons.org/licenses/by/2.0), which permits unrestricted use, distribution, and reproduction in any medium, provided the original work is properly cited.
Received: 13 March 2008

Accepted: 7 January 2009

\section{Background}

Enteric fever continues to be a major health problem in developing countries. In Nepal, Salmonella enterica serotypes Typhi and Salmonella enterica serotype Paratyphi A are common causative organisms for typhoid and paraty-

\begin{abstract}
Background: Enteric fever is an endemic problem in Nepal and Widal agglutination test is widely used for its diagnosis but a normal baseline titer in healthy population and cutoff values have not been established.

Methods: We measured average baseline antibody titers against "O" and " $\mathrm{H}$ " antigens of Salmonella enterica serotype Typhi and " $\mathrm{H}$ " antigens of serotypes Paratyphi $A$ and Paratyphi B among apparently healthy blood donors in Nepal. The antibody titers were measured using Standard Widal Confirmatory Quantitative Tube test.

Results: Among the 100 blood samples collected from healthy volunteers, 62 individuals had significant antibody titers $(\geq 1: 20)$ against one of the four antigens against $S$. enterica. Among 54 samples with an anti-O titer against serotype Typhi, I5 and 36 samples had titers of $\geq 1: 60$ and $\geq$ $\mathrm{I}: 40$, respectively. A significant proportion ( $12 \%$ of all) had anti-O titer of $\geq \mathrm{I}: 80$. Similarly, among the 59 samples demonstrating anti-H titers of $\geq 1: 20$ to $S$. enterica serotype Typhi, 29 had a titer of $\geq \mathrm{I}: 80$ and $\mathrm{I} 2$ had I:I60. For S. enterica serotypes Paratyphi $A$ and $B$, anti-H titers of $\geq I: 20$ were found only in $12 \%$ and $3 \%$, respectively, of all samples tested.

Conclusion: When a single Widal agglutination titer is used for the diagnosis of enteric fever, it will be more appropriate to change the currently used cutoff levels against $S$. enterica serotype Typhi to $>\mathrm{I}: 80$ for anti-O and > I:I60 for anti-H titers for Nepal.
\end{abstract}


Definitive diagnosis of enteric fever depends on isolation of salmonellae from blood, stool, urine, bone marrow, bile or other body fluids [5-7]. However, it is a relatively costly method and is not always available in less developed countries such as Nepal. Widal agglutination test is an alternative laboratory test widely used for serological diagnosis of enteric fever in these settings. Developed by Georges Fernand Isidore Widal in 1896 to aid in the diagnosis of typhoid fever, Widal test utilizes a suspension of killed Salmonella enterica as antigen to detect typhoid fever in serum of patients with suspected enteric fever $[8,9]$. The test is based on demonstration of the presence of agglutinin (antibody) in the serum of an infected patient, against the $\mathrm{H}$ (flagellar) and $\mathrm{O}$ (somatic) antigens of Salmonella enterica serotype typhi, paratyphi $A$ and paratyphi $B$, during the acute and convalescent period of infection [10]. Usually up to $70 \%$ of adults show an early rise of antibody titer in the first week of infection [11].

Antibody titer may be high in healthy individuals in the presence of cross reacting antigens, such as malaria, brucellosis, dengue fever, healthy carrier state, chronic liver disease, endocarditis or other enterobacteriaceae infections [12]. There are more than 40 cross-reacting antigens between $S$. typhi and other enterobacteriaceae [13]. Persons who had past enteric infection or vaccinated with the old typhoid vaccine (TAB) may develop transient anamnestic reaction during an unrelated febrile illnesses, such as malaria [14]. Epidemiology of cross-reacting antigens determines the baseline titer of Widal test as antibody produced in these diseases may cross-react with Salmonella antigens. Therefore, a four fold rise in antibody titers between acute and convalescent phases is considered as a significant change in a given person. Since this type of comparison is not practically helpful in establishing diagnosis of an acute illness, a single cutoff value is widely used. In a given population, interpretation of a single Widal test result needs to be based on average baseline titer among the healthy individuals. Antibody titers beyond a cut off value should be regarded as significantly elevated titers which may be used for diagnosis in an appropriate clinical stetting.

Normal baseline titers of Widal agglutination test for healthy individuals and cutoff values for diagnosis of enteric fever in Nepal have not been established. This project was designed to determine the baseline population antibody titers. The secondary objective was to calculate minimum titers required to make diagnosis of typhoid and paratyphoid fever in Nepal.

\section{Methods}

This study was conducted at Tribhuvan University Teaching Hospital (TUTH), which is a tertiary care and academic center of 450 beds located in Kathmandu, Nepal.
This hospital's microbiology laboratory also provides service as a referral center for many other clinics in the Kathmandu valley and other parts of Nepal.

The objective of this project was to determine the average baseline antibody titer against Salmonella enterica among the apparently healthy people of Kathmandu valley. Blood samples were collected from the blood donation program organized by local youth club in association with TUTH Blood Bank Department. Health screening of the volunteer donors was done using survey questionnaires. All the donors were apparently healthy. Individuals with an active infection or a recent infection including tuberculosis, hepatitis, enteric fever, malaria or HIV/AIDS were excluded.

Total 135 units of blood were collected from 135 apparently healthy individuals and 100 bags were randomly selected to collect blood for the study. About $2.0 \mathrm{ml}$ of blood was taken from the tubes of each bag that were not diluted by CPDA 1 present inside the blood bags. Serum was separated immediately, labeled and stored in at $20^{\circ} \mathrm{C}$ for further processing.

The serum samples were processed according to standard tube dilution method. Antigen suspensions of Salmonella enterica serotypes typhi, paratyphi $A$ and $B$ in normal saline were used for the Confirmatory Quantitative Tube Test. The "O" and " $\mathrm{H}$ " antigens were stabilized suspensions of smooth, non-fimbriate, killed bacilli, which were standardized to produce appropriate reactivity. When the colored, smooth attenuated antigen suspensions were mixed and incubated with individual's serum, anti-salmonella antibodies present in the serum react with the corresponding antigens to give agglutination. The "O" antigen being a somatic antigen brings about a coarse, compact, granular agglutination whereas " $\mathrm{H}$ " antigen being a flagellar antigen brings about larger, loose, fluffy agglutination $[15,16]$. The IgM somatic "O" antibody appears first and represents the initial serologic response in acute typhoid fever, while the IgG flagellar " $\mathrm{H}$ " antibody usually develops more slowly but persists for longer.

All the serum samples were first diluted in 1:20 ratio with isotonic normal saline $(8.5 \mathrm{~g} /$ liter $)$ in such a way that final volume contained a total of $1 \mathrm{ml}$. For each sample four dilutions were made in four test tubes. Similarly, the polyspecific control was also diluted in the same manner. Then one drop $(0.03 \mathrm{ml})$ each of the antigen suspensions was added to corresponding tubes. All tubes were mixed well and incubated at $37^{\circ} \mathrm{C}$ overnight (16-20 hours). Next day, each tube was observed for the agglutination.

The test results were scored as following: 0 (no agglutination $), 1+(25 \%$ agglutination $), 2+(50 \%$ agglutination $)$, 
$3+(75 \%$ agglutination $)$ and $4+(100 \%$ agglutination $)$ [17]. For visualization and test to be assumed as positive, there should be at least 50\% agglutination. Initial positive screening tests were further diluted for the determination of the strength of antibodies. Weakly reactive agglutinations required an adequate light source for proper visualization.

According to World Health Organization, Regional Office for South-East Asia, dilution should begin with 1:10 and doubled through 1:320 or so, and $0.5 \mathrm{ml}$ of antigen suspension should be mixed with $0.5 \mathrm{ml}$ of serum for dilution [18]. As there was a great gap between the two dilutions, the positive samples were diluted further at the interval of 20 and only $0.03 \mathrm{ml}$ of antigen suspension was used according to Ranbaxy Fine Chemical Limited Diagnostic Division, India and Tulip Diagnostics (P) Ltd, India. For quality control, the positive polyspecific control was also processed in the same dilutions as the test sample. Similarly normal saline was used for a negative control. Positive serum samples were diluted for each antibody as described before.

Finally, the maximum dilution that exhibits $2+$ or $50 \%$ agglutination was considered as the end point of serum activity and recorded as the titer of antibodies present in the individuals against salmonella [17].

\section{Results}

A total of 100 blood samples were collected from apparently healthy persons from Kathmandu valley from July to August 2006. Samples were collected from apparently healthy individuals of different age groups from 18 to 50 years. As very few females donated blood, only 14 blood samples were collected from women. All the individuals were from different places of Kathmandu valley which has three cities-Kathmandu, Patan and Bhaktapur (Table 1). None of the volunteers had a history of recent infections, including malaria, viral hepatitis, tuberculosis, HIV infection, sexually transmitted diseases, or other infectious diseases. They were also excluded for any active cardiac, lung or kidney diseases.

The antibody titers against various Salmonella enterica serotypes were determined on the separated serum by Standard Widal Confirmatory Tube method. Among the total 100 samples tested, 62 samples showed agglutination at the titer $\geq 1: 20$ for the $\mathrm{O}$ or $\mathrm{H}$ antibodies against Salmonella enterica serotypes Typhi, Paratyphi A or Paratyphi $B$ (Figure 1). Rest of the 38 samples did not show agglutination. The distribution of individual antibodies with positive titers $(\geq 1: 20)$ was as shown in Table 2 .

The distribution of 54 samples with an anti-O titer of $\geq$ 1:20 to Salmonella enterica serotype Typhi showed that a
Table I: Demographic table showing distribution of individuals according to age group, sex and city

\begin{tabular}{lcc}
\hline & Frequency & Percentage \\
\hline Total no. of individuals & 100 & $100 \%$ \\
\hline Age groups: & & \\
$<20$ years & 11 & $11 \%$ \\
$20-30$ years & 66 & $66 \%$ \\
$31-40$ years & 19 & $19 \%$ \\
$41-50$ years & 4 & $4 \%$ \\
\hline Gender: & & \\
$\quad$ Male & 86 & $86 \%$ \\
$\quad$ Female & 14 & $14 \%$ \\
\hline Cities: & & \\
$\quad$ Kathmandu & & $89 \%$ \\
Patan & 89 & $6 \%$ \\
Bhaktapur & 6 & $5 \%$ \\
\hline
\end{tabular}

significant proportion of the samples ( $15 \%$ of all samples tested) had a titer $\geq 1: 60$ while more than $1 / 3^{\text {rd }}$ (36\% of all samples) had a titer of $\geq 1: 40$ (Figure 2 ). Of note, a significant proportion of blood samples (12 individuals) had an anti-O titer of 1:80. The median and mean antibody titers against the "O" antigen were 1:20 and 1:30 (standard deviation $\geq 1: 30$ ).

Similarly, among the 59 samples showing anti-H titer of $\geq$ 1:20 to Salmonella enterica serotype Typhi, 29 of samples were positive at a titer of $\geq 1: 80$ and 12 had a titer of $1: 160$. The highest titer of $1: 1120$ was found in one sample (Figure 3). The median and mean antibody titers against the " $\mathrm{H}$ " antigen were 1:20 and 1:64 (standard deviation $=1: 123$ ).

Altogether 12 samples showed agglutination titer of $\geq$ 1:20 against $\mathrm{H}$-antigen of Salmonella enterica serotype Paratyphi A among which 8 samples had $\geq 1: 40$ and 1 had $\geq 1: 80$ titers (Figure 4 ). The median and mean antibody

Table 2: Distribution of the samples with antibody titer $\geq 1: 20$ against different serotypes of Salmonella enterica (Total number of samples, $\mathbf{N}=100$ )

\begin{tabular}{llll}
\hline Serotype & Antibody Type & Frequency & Percentage \\
\hline Typhi & Anti-O antigen & 54 & $54 \%$ \\
\hline Typhi & Anti-H antigen & 59 & $59 \%$ \\
\hline Paratyphi A & Anti-H antigen & 12 & $12 \%$ \\
\hline Paratyphi B & Anti-H antigen & 3 & $3 \%$
\end{tabular}




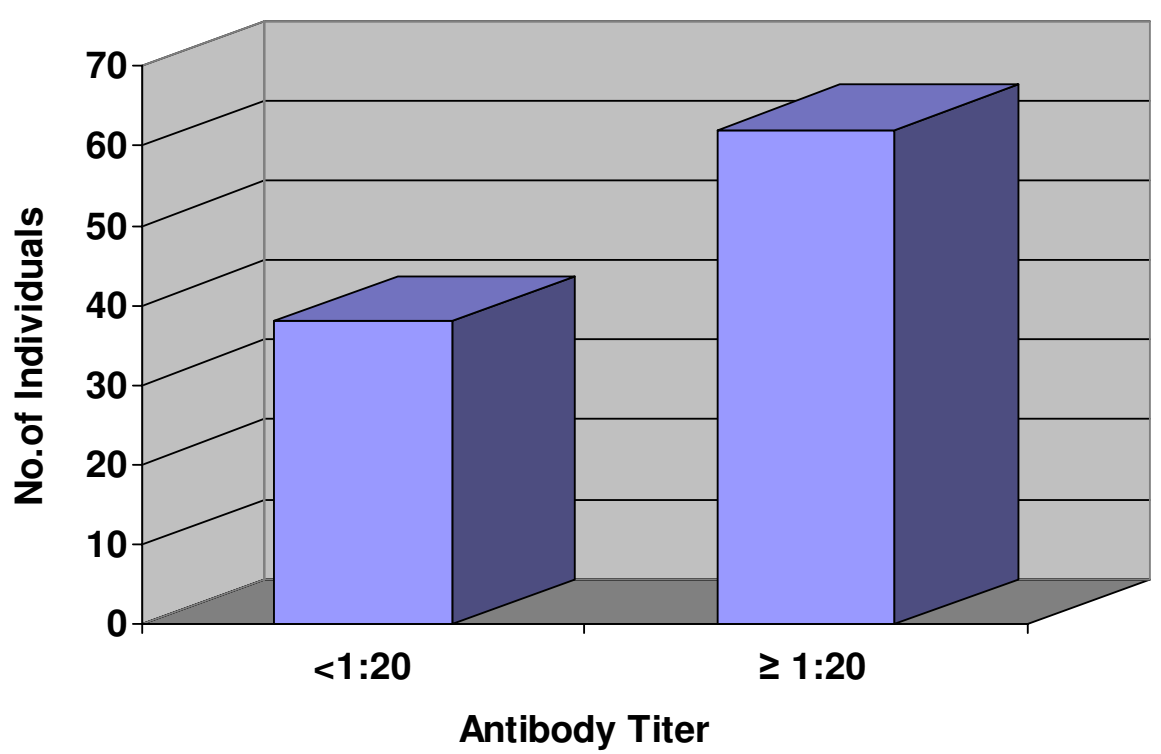

Figure I

Proportions of samples with antibody titers $<\mathrm{I}: 20$ vs. $\geq \mathrm{I}: 20(\mathrm{~N}=\mathrm{I} 00)$.

titers against the " $\mathrm{H}$ " antigen of serotype Paratyphi A were $1: 10$ and $1: 13$ (standard deviation $=1: 10$ ).

Only 3 samples had anti-H titer of $\geq 1: 20$ to $\mathrm{H}$-antigen of Salmonella enterica serotype Paratyphi $B$.

\section{Discussion}

Although preferred laboratory procedure for identification of Salmonella enterica is culture, most clinics and hospitals in developing countries do not have ready access to this method. Widal agglutination tests are widely used in many developing countries, including Nepal, as an alternative laboratory procedure for diagnosis of enteric fever.

This is the first study done in Nepal which was designed to determine the average baseline antibody titer in healthy individuals against various serotypes of $S$. enterica using the Widal test. This study showed that varying amount of antibody against Salmonella enterica is present in healthy individuals. A significant proportion of healthy individuals had high titers indicating a need of reevaluation of the current cutoff values for diagnostic titer.

In acute typhoid fever, a rise in the anti-O antibody titer followed by a gradual elevation of anti-H antibody titer occurs. The anti-H antibody response persists longer than the anti-O antibody $[19,20]$. The result of our study confirmed the presence of high agglutinin titers even in a significant proportion of healthy individuals. We found that $15 \%$ of these samples had anti-O antibody titers of $\geq 1: 80$ and $16 \%$ had anti-H antibody titers of $\geq 1: 160$ against Sal- monella enterica serotype Typhi. In Nepal, the current reference baseline titer of Widal agglutination test for diagnosis of typhoid fever is 1:80 for both $\mathrm{O} \& \mathrm{H}$ agglutinins. Therefore, the levels of agglutinins for Salmonella typhi in these healthy individuals were greater than those used to diagnose typhoid fever currently in Nepal. According to these results, significant titers should be greater than 1:80 for anti-O and greater than 1:160 for anti-H for a presumptive diagnosis of typhoid fever. The latter titers are similar to what has been reported from India [21]. Similarly, a study in Vietnam found that using Widal test cutoff titers of $\geq 1: 200$ for $\mathrm{O}$ agglutinin or $\geq 1: 100$ for $\mathrm{H}$ agglutinin correct diagnosis was established in $74 \%$ of the blood culture positive cases of typhoid fever [13]. Other studies also reported that a cutoff value of anti-O titer $\geq$ 1:160 using Widal agglutination test was more predictive of Salmonella enterica infection [22,23]. It also appeared that anti-H titer was more useful than anti-O titer [23].

Proper hygiene and sanitation is the main cause of low prevalence of enteric fever in developed countries, resulting low antibody titer. A study in Singapore showed that all the patients with non-typhoid fever had an anti-O agglutinin titer of less than 1:40, while $82 \%$ had an anti$\mathrm{H}$ agglutinin of less than 1:40 [24]. They found that typhoid patients with titers $\geq 1: 40$ for $\mathrm{O}$ and $\mathrm{H}$ antigens of Salmonella typhi were significantly different from those from non-typhoid fever. It concluded that the baseline titer for Widal test is lesser in developed countries than in developing countries. 


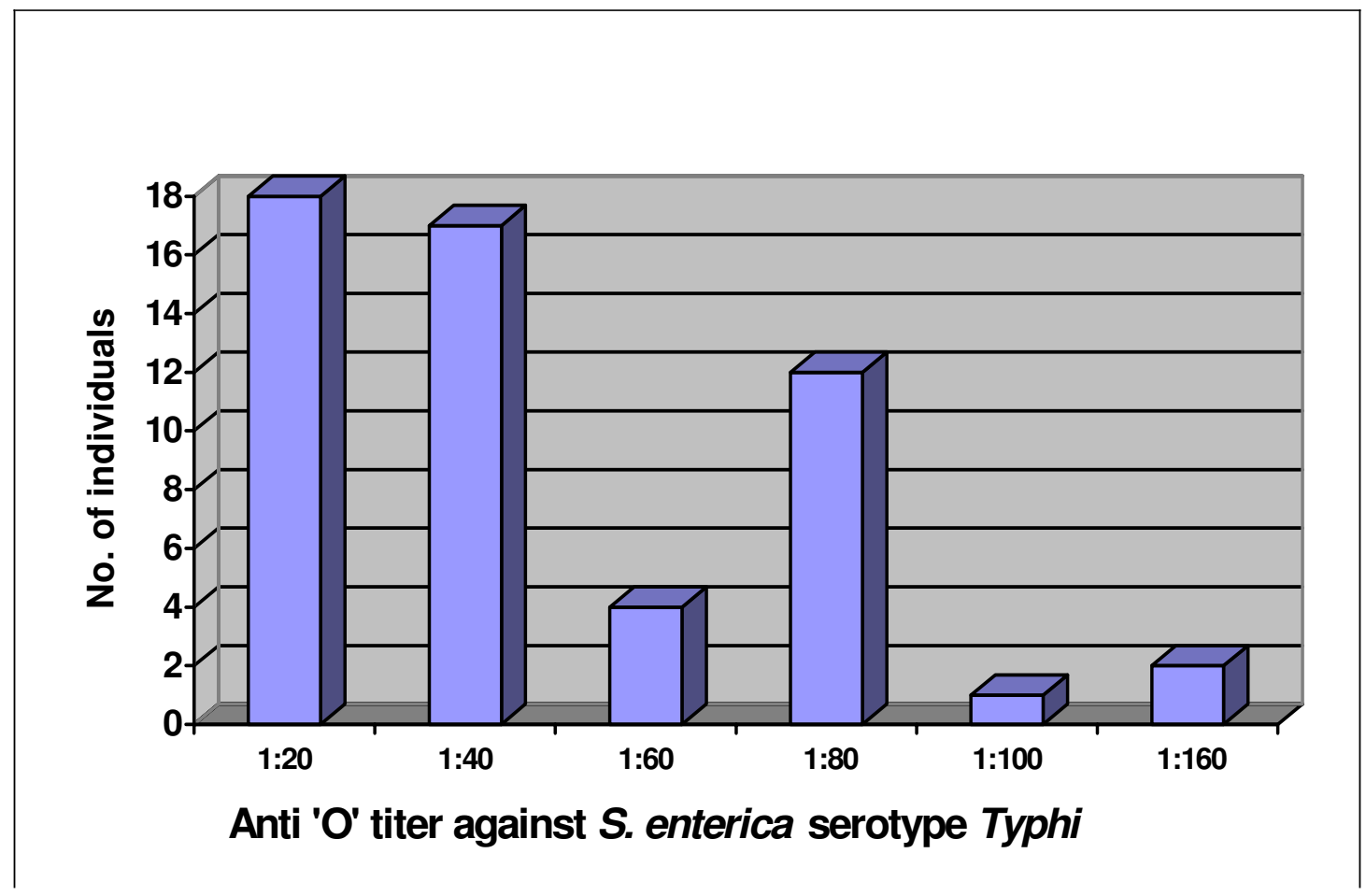

Figure 2

Distribution of 54 samples with anti-O titer $\geq$ I:20 against Salmonella enterica serotype Typhi.

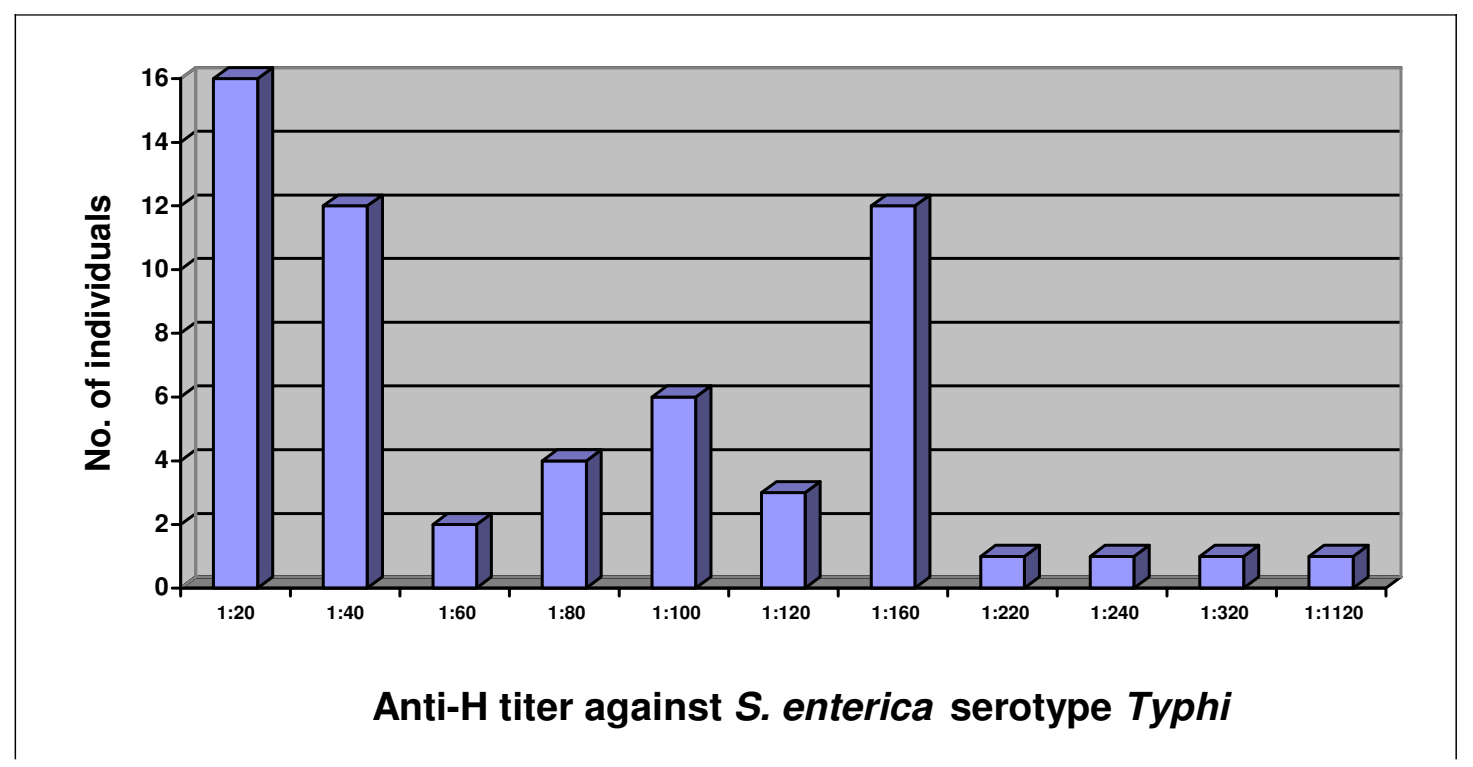

Figure 3

Distribution of 59 samples with anti-H titer $\geq$ I:20 for Salmonella enterica serotype Typhi. 


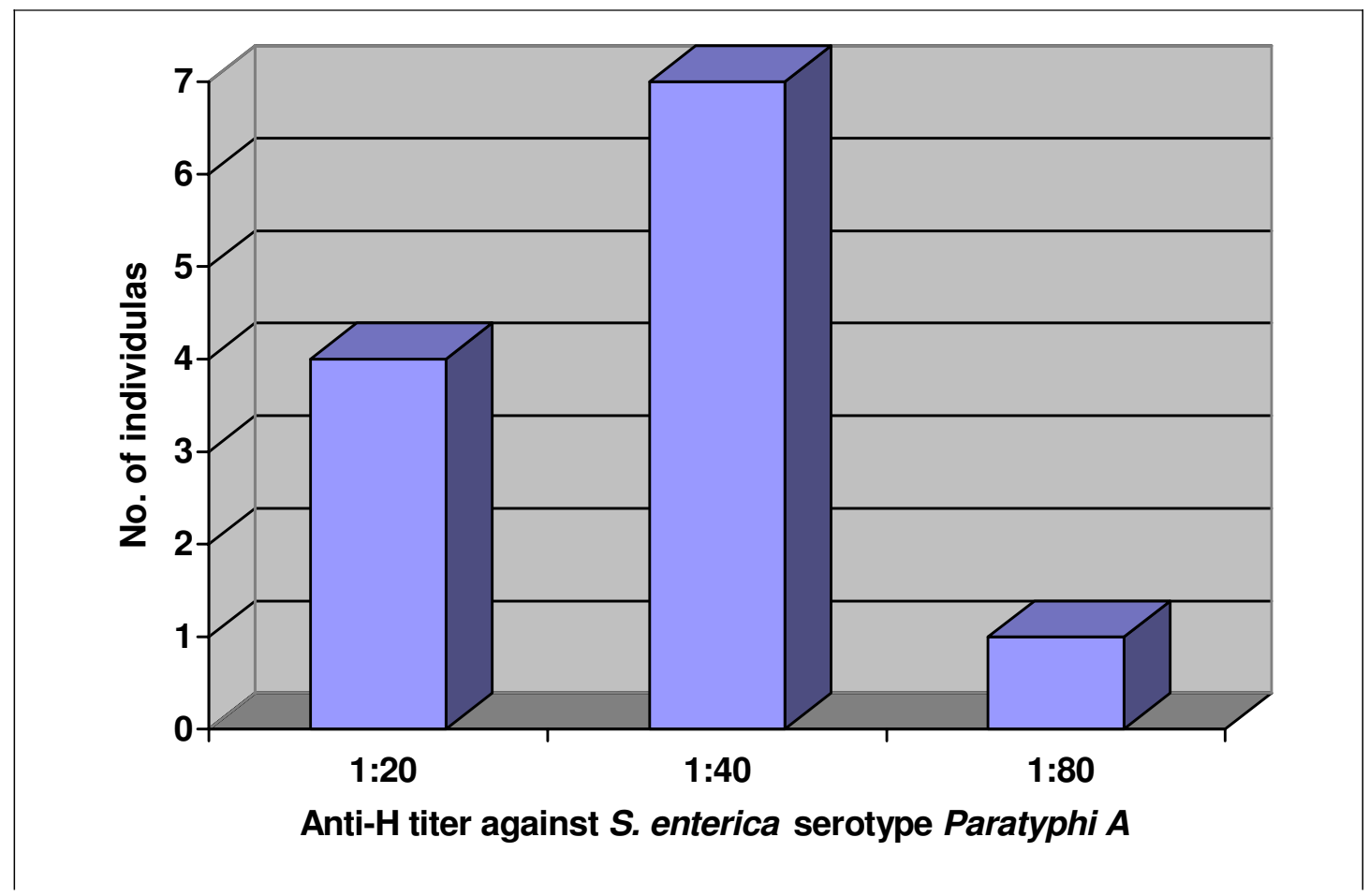

Figure 4

Distribution of 12 samples with anti - H titer $\geq$ I:20 for Salmonella enterica serotype Paratyphi A.

In our study, the maximum anti-O and anti-H titers against $S$. enterica typhi were 1:160 \& 1:1120 in $2 \%$ and $1 \%$, respectively, which may be due to other recent acute infections. In a case report of a patient with Salmonellla javiana in stool, the Widal reaction to typhoid "O" antigen was $1: 320$ which increased to $1: 20,480$ by fourth day after admission. Although initially suspected to have enteric fever, the patient's blood and urine cultures were negative for S. enterica [25]. Elevated levels of anti-O and anti-H agglutinins against $S$. enterica have been reported in patients with a variety other infections including those caused by other Salmonella spp., E. coli, Klebsiella spp., and Staphylococcus aureus [26,27]. Studies in Nigeria showed that $85 \%$ of patients with a negative Salmonella enterica culture but positive malaria smear had Widal titer of 1:40, $12 \%$ had titer of $1: 80$, and $3 \%$ had titer of $1: 160[28,29]$.

Our study also showed that anti-H agglutinin titer to Salmonella enterica serotype Paratyphi A in Kathmandu Valley was less than that against Salmonella enterica serotype Typhi. Only 8 individuals had anti-H titer $\geq 1: 40$ and only one had a titer of 1:80. The currently used cutoff value for anti-H titer against $S$. enterica serotype Paratyphi $A$ in Nepal is $\geq 1: 80$. Only three individuals developed significant levels of anti-H titer against Salmonella enterica sero- type Paratyphi $B$, which suggests that it is a rare serotype in Kathmandu valley.

The Widal test results may depend on the levels of antibodies to cross-reacting antigens to various salmonella species. In the Kauffmann-White classification, the genus Salmonella issubdivided into more than 2300 serotypes containing different combinations of antigens [30]. Salmonellae are divided into serological groups on the basis of $\mathrm{O}$ or somatic antigens. About 60 of the 78 group $\mathrm{D}$ organisms, including S. enterica serotype Typhi, and group $A$ and B organisms, such as S. enterica serotypes Paratyphi $A$ and $B$, also have antigen 12. Other Salmonellae share the $\mathrm{H}$ (flagellar) antigens with $S$. enterica serotype Typhi. Cross-reactions producing a false positive anti-O titer in the Widal test can therefore occur with any of these serotypes [31]. False positive Widal test results are observed in individuals with salmonella infections other than enteric fever, malaria, cryptococcal meningitis, immunological disorders, and chronic liver failure. Septicemia, malaria and dengue are other common causes of fever requiring hospital admission which may be confused with enteric fever because of a false positive agglutination test. These can be differentiated from enteric fever by other appropriate investigations [32,33]. Studies support that re-evalua- 
tion of the Widal baseline titer for healthy individuals should be done at regular intervals [34].

\section{Conclusion}

The diagnosis of enteric fever should be established by culture. When cultures are not available, demonstration of a four-fold or greater rise in titer of both $\mathrm{H}$ and $\mathrm{O}$ agglutinins in paired sera at an interval of 4 to 7 days is recommended for serodiagnosis of enteric fever. However, a single Widal test with higher titer may be the only method available for presumptive diagnosis of enteric fever in developing countries as patients usually attend hospitals late in course of disease. In this setting, the Widal agglutination should be carefully interpreted based on the prevalent local baseline titer. Based on the results of this study, we recommend to change the currently used cutoff levels for single antibody titers against Salmonella enterica serotype Typhi to $>$ 1:80 for anti-O and $>1: 160$ for anti-H titers for Kathmandu valley.

\section{Competing interests}

Bharat M Pokhrel - None.

Rajendra Karmacharya - None.

Shyam K Mishra - None.

Janak Koirala - Dr. Koirala has done clinical studies for NIH/CPCRA, American Lung Association, Pharmacia, Pfizer, BMS and Theravance.

\section{Authors' contributions}

All authors contributed equally to this work.

\section{Acknowledgements}

We thank Alys Adamski for helping us with the manuscript preparation and submission.

\section{References}

I. Pokharel BM, Koirala J, Dahal RK, Mishra SK, Khadga PK, Tuladhar NR: Multidrug-resistant and extended-spectrum beta-lactamase (ESBL)-producing Salmonella enterica (serotypes Typhi and Paratyphi $A$ ) from blood isolates in Nepal: surveillance of resistance and a search for newer alternatives. Int J Infect Dis 2006, I 0:434-8.

2. Maskey AP, Basnyat B, Thwaites GE, Campbell JI, Farrar JJ, Zimmerman MD: Emerging trends in enteric fever in Nepal: 9124 cases confirmed by blood culture 1993-2003. Trans $R$ Soc Trop Med Hyg 2008, I 02:9|-5.

3. Parker MT, Collier LH: Topley \& Wilson's Principle of bacteriology, Virology \& Immunology London, Edward Arnold; 1990:487.

4. Chakrabarty P: A textbook of Microbiology Kolkata, NC Book agency; 2001:332.

5. Manson-Bahr PEC, Bell DR: Manson's tropical diseases London, Bailliere-Tindall; 1987: 194-206.

6. Gilman RH, Terminel M, Levine MM, Hernandez-Mendoza P, Hornick $\mathrm{R}$ : Comparison of relative efficacy of blood, stool, urine, bone marrow and rose spot cultures for recovery of Salmonella typhi in typhoid fever. Lancet 1975, I:I21 I-I215.

7. Geddes AM: Imported infections. Unexplained fever. $B M J$ 1974, 4:397-398.
8. Donal V: Taber's cyclopedic Medical Dictionary Philadelphia, FA Davis; 200I:2363.

9. Cruickshank R: Medical Microbiology London, Churchill Livingston; 1982:403.

10. Washington JA, Henry JB: Medical microbiology in clinical diagnosis and management by laboratory methods Philadelphia, WB Saunders; 1984:1102.

II. Chessbrough M: Medical Laboratory Manual for Tropical Countries Cambridge, ELBS; 1987:260-6I.

12. Colle JG, Frason AG, Marmion BP, Simmons A: Mackie and Mc Cartney Practical Medical Microboiology New York, Churchill Livingston; 1996:389.

13. Parry CM, Hoa NT, Diep TS, Wain J, Chinh NT, Vinh H, Hien TT, White NJ, Farrar J]: Value of a single-tube widal test in diagnosis of typhoid fever in Vietnam. J Clin Microbiol 1999, 37:2882-6.

14. Ananthanarayan R, Paniker CKJ: Textbook of Microbiology Hyderabad, Orient Longman; 2003:275-76.

15. Welch H, Staurt CA: J Lab Clin Med 1936, 2 I:4II.

16. Protell RL, Soloway RD, Martin WJ, Schoenfield LJ, Summerskill WH: Anti-Salmonella agglutinins in chronic active liver disease. Lancet 1971, 2:330-2.

17. Lynch MJ, Raphael SSL: Lynch's Medical Laboratory Technology Philadelphia, WB Saunders; 1976:728.

18. World Health Organization: Blood Safety and Clinical Technology. Guidelines on Standard Operating Procedures for Microbiology [http://
[ searo.who.int/EN/Section I0/Section I7/Section53/

Section482 1794.htm]. (Accessed on: December 2007)

19. Typhoid and its serology. BMJ 1978, I:389-390.

20. Hoffman SL, Flanigan TP, Klancke D, et al.: The Widal slide agglutination test, a valuable rapid diagnostic test in typhoid fever patients at the infectious disease hospital in Jakarta. Am J Epidemiol 1986, I 23:869-875.

21. Punia JN, Joshi RM, Gupta V, Arora RK: Determination of baseline widal titers from Chandigarh. Indian J Med Microbiol 2003, 2 I : 44.

22. Hamze M, Vincent P: Typhoid fever in north Lebanon: a 8-year study (1 992-1999) using the Widal test. East Mediterr Health J 2004, 10:180-6.

23. Abraham G, Teklu B, Gedebu M, Selassie GH, Azene G: Diagnostic value of the Widal test. Trop Geogr Med I98I, 33:329-33.

24. Chew SK, Cruz MS, Lim YS, Monteiro EH: Diagnostic value of the Widal test for typhoid fever in Singapore. J Trop Med Hyg 1992, 95:288-9l.

25. Sansone $\mathrm{P}$, Saslaw $\mathrm{MS}$, Hennekens $\mathrm{CH}$ : High titer Widal reaction. JAMA 1972, 220:1615-6.

26. Olopoenia L, Oyewole F, Onafowokan R, et al.: Widal agglutination in malaria infection. Med Rev 1996, 3:5-6.

27. Levine MM, Grados O, Gilman RH, Woodward WE, Solis-Plaza R, Waldman W: Diagnostic value of the Widal test in areas endemic for typhoid fever. Am J Trop Med Hyg 1978, 27:795-800.

28. Mohammed I, Chikwem JO, Gashau W: Determination by Widal agglutination of the baseline titer for the diagnosis of typhoid fever in two Nigerian states. Scand J Immunol Suppl 1992, I I:I53-6.

29. Zailani SB, Ovelese AO, Aboderin AO: Determination of baseline antibody titer to S. typhi/paratyphi in Ile-Ife, Nigeria. Afr J Med Med Sci 2003, 32:307-10.

30. Esperson F, Hoiby N, Herts JB: Cross reaction between Salmonella typhi and 24 other bacterial species by CIEP. Acta Pathol Microbiol Scand 1980, 81:243-248.

3I. Mandell GL, Bennett JE, Dolin R: Mandell, Douglas, and Bennett's Principles \& Practice of Infectious Diseases Philadelphia, Elsevier; 2006: $1256-1267$.

32. Hoa NTT, Diep TS, Wain J, Parry CM, Hien TT, Smith MD, Walsh $A M$, White NJ: Community-acquired septicaemia in an infectious diseases hospital in Viet Nam. The importance of multi-drug resistant. Salmonella typhi 1998, 92(5):503-508.

33. Vaughn DW, Nisalak A, Kalayanarooj S, Solomon T, Dung NM, Cuzzubbo A, Devine PL: Evaluation of a rapid immunochromatographic test for diagnosis of dengue infection. J Clin Microbiol 1998, 36:234-238.

34. Clegg A, Passey M, Omena M, Karigifa K, Suve N: Re-evaluation of the Widal agglutination test in response to the changing pattern of typhoid fever in the highlands of Papua New Guinea. Acta Trop 1994, 57:255-63. 